\title{
Changes in intraocular pressure during surgery in the lateral decubitus position under sevoflurane and propofol anesthesia
}

\author{
Makiko Hardy Yamada ${ }^{1}$ Tomonori Takazawa ${ }^{1}$ - Nobuhisa Iriuchijima ${ }^{2}$. \\ Tatsuo Horiuchi ${ }^{1} \cdot$ Shigeru Saito ${ }^{1}$
}

Received: 16 April 2015/Accepted: 30 September 2015/Published online: 6 October 2015

(C) The Author(s) 2015. This article is published with open access at Springerlink.com

\begin{abstract}
Intraocular pressure (IOP) has been shown to change with body position. Several studies have shown that the lateral decubitus position (LDP) is associated with a significant increase in IOP in the dependent eye. However, whether anesthetic agents alter IOP in the LDP remains unclear. This study investigated the effect of sevoflurane and propofol anesthesia on IOP in the LDP. A total of 28 patients undergoing surgery in the LDP were included. Patients were randomly allocated to sevoflurane or propofol groups. IOP in both eyes was recorded and compared between groups at five time points: after anesthesia induction, after endotracheal intubation, at $5 \mathrm{~min}$ and $1 \mathrm{~h}$ after a positional change to the LDP, and $5 \mathrm{~min}$ after returning to the supine position. In the sevoflurane group, IOP was significantly increased in both dependent and nondependent eyes $1 \mathrm{~h}$ after changing to the LDP. In the propofol group, IOP decreased in both dependent and nondependent eyes after tracheal intubation, but did not increase after changing to the LDP. The number of patients in whom IOP increased to $\geq 28 \mathrm{mmHg}$ was greater in the sevoflurane group than in the propofol group. Propofol may be better than sevoflurane for the maintenance of anesthesia in the LDP. Monitoring of IOP in the LDP might help avoid ophthalmic complications.
\end{abstract}

Tomonori Takazawa

takazawt@gunma-u.ac.jp

1 Department of Anesthesiology, Gunma University Graduate School of Medicine, 3-39-22 Showa-machi, Maebashi 371-8511, Japan

2 Department of Anesthesiology, Kiryu Kosei General Hospital, 6-3 Orihime-cho, Kiryu 376-0024, Japan
Keywords Intraocular pressure $\cdot$ Lateral decubitus position $\cdot$ Sevoflurane $\cdot$ Propofol

\section{Introduction}

Intraocular pressure (IOP) is influenced by several factors, including changes in body position. For example, IOP is known to increase in the lateral decubitus position (LDP) in both awake healthy subjects and glaucoma patients [1-6]. Recent evidence indicates that increases in IOP are not directly related to the development of ischemic optic neuropathy, which is the most common cause of postoperative visual loss (POVL) [7]. However, increased IOP is likely to be a risk factor for other ophthalmic complications, including anterior ischemic optic neuropathy, retinal artery occlusion, and deterioration of preoperative glaucoma [8]. Therefore, monitoring IOP during general anesthesia may allow anesthesiologists to reduce the risk of perioperative ophthalmic complications.

Previous reports have documented the potential risk of ophthalmic complications during anesthesia in the LDP. One case report describes a 59-year-old woman who suffered complete visual loss in the dependent eye after spine surgery in the LDP [9]. In addition, two cases of POVL in which spine surgery was performed in the LDP are included in the American Society of Anesthesiologists (ASA) POVL Registry [10]. Despite these case reports, the effect of the LDP on IOP during general anesthesia still remains to be elucidated. The sole study addressing this issue demonstrated that IOP was significantly increased, particularly in the dependent eye, in the LDP [11].

Anesthetic agents that are appropriate for management of IOP intraoperatively would be of interest to anesthesiologists. In the supine position, significant reductions in 
IOP after induction and maintenance of anesthesia with both sevoflurane and propofol have been reported [12], while IOP values during laparoscopic gynecological procedures in the Trendelenburg position under isoflurane anesthesia were higher than those under propofol anesthesia [13]. In addition, the reduction in IOP during cataract surgery in the supine position was significantly more pronounced under propofol anesthesia compared with sevoflurane anesthesia [14]. In contrast, no significant difference in IOP was seen during spine surgery in the prone position under sevoflurane anesthesia compared with propofol anesthesia [15]. Therefore, it remains controversial whether volatile or intravenous anesthetic agents are preferable to avoid abnormal changes in IOP.

Besides IOP, ocular perfusion pressure (OPP) has also been implicated as an important factor in ophthalmic diseases such as glaucoma [4]. OPP is the driving force for ocular blood flow, and low or unstable OPP has been associated with the development or progression of openangle glaucoma [16]. However, few studies have reported on changes in OPP during surgery in the LDP. The purpose of this study was to investigate the changes in IOP and OPP during surgery in the LDP under sevoflurane and propofol anesthesia.

\section{Methods}

After approval by the human studies committee, written informed consent for participation in the study was obtained from 28 patients scheduled for surgery in the LDP between July 2007 and February 2010. Patients who had glaucoma and ophthalmic disease other than myopia or hypermetropia were excluded. All patients were randomly assigned to either a sevoflurane group $(n=14)$ or a propofol group $(n=14)$. In the sevoflurane group, 10 patients had a lung operation, 3 had hip replacement arthroplasty, and 1 had a femoral plate removed. In the propofol group, 11 patients had a lung operation, while three had a nephrectomy. No premedication was given to patients before anesthesia. Anesthesia was induced with $1.8-2.5 \mathrm{mg} / \mathrm{kg}$ propofol in the sevoflurane group, and with a target-controlled infusion (TCI) of propofol (3.0-5.0 $\mu \mathrm{g} /$ $\mathrm{ml})$ in the propofol group. Simultaneously, $0.2-0.5 \mu \mathrm{g} / \mathrm{kg} /$ min remifentanil was administered for induction of anesthesia in both groups. Vecuronium $(0.12-0.15 \mathrm{mg} / \mathrm{kg})$ or rocuronium $(0.65-0.9 \mathrm{mg} / \mathrm{kg})$ was administered to facilitate tracheal intubation. Mechanical ventilation was started and adjusted to maintain the end-tidal $\mathrm{CO}_{2}\left(\mathrm{ETCO}_{2}\right)$ partial pressure between 25 and $40 \mathrm{mmHg}$. A 22-gauge catheter was placed in the radial artery in the dependent arm to monitor arterial pressure. After induction of anesthesia, all patients were turned from the supine position to the LDP.
None of the patients adopted a low head position in the LDP. A soft pillow was inserted under the head to maintain the head parallel to the center of the thoracic vertebra. The absence of extraocular pressure from a sponge pillow was confirmed. Anesthesia was maintained with 1.5-2.0\% sevoflurane in the sevoflurane group and with a TCI of propofol $(2.8-4 \mu \mathrm{g} / \mathrm{ml})$ in the propofol group. Intermittent bolus injections of 50-100 $\mu \mathrm{g}$ fentanyl and/or a continuous infusion of $0.1-0.3 \mu \mathrm{g} / \mathrm{kg} / \mathrm{min}$ remifentanil were given for maintenance of general anesthesia in both groups. The depth of anesthesia was controlled clinically with the aim to maintain vital signs within $\pm 20 \%$ of the preoperative value. Muscle relaxant agents were used as needed intraoperatively. After completion of the surgical procedure, the patients were moved back to the supine position. Upon arousal from anesthesia, the patients were asked about any vision changes or ocular discomfort.

$\mathrm{IOP}$, mean blood pressure (mBP), heart rate, and $\mathrm{ETCO}_{2}$ were recorded at the following five time points: (T1) in the supine position, after induction of anesthesia by propofol, and before injection of the muscle relaxant (defined as control); (T2) after tracheal intubation and just before injection of the muscle relaxant; (T3) 5 min after positioning in the LDP; (T4) $1 \mathrm{~h}$ after adoption of the LDP; and (T5) 5 min after changing back to the supine position.

IOP was measured with Tono-Pen ${ }^{\circledR}$ XL Applanation tonometer (Reichert, Depew, NY, USA). This instrument measures and calculates IOP by the principle of the ImbertFick law $(\mathrm{P}=\mathrm{F} / \mathrm{A}$, where $\mathrm{P}=\mathrm{IOP}, \mathrm{F}=$ the force exerted by the tonometer to flatten a specific area of the eye, and $\mathrm{A}=$ the area flattened). Each IOP datum was obtained by the calculated average of three successful tonometer measurements, the range of difference of which was $<10 \%$. The Tono-Pen was calibrated before measurements. IOP of the right eye was always measured first. OPP was calculated according to the formula: $\mathrm{OPP}=115 / 130 \times \mathrm{mBP}-\mathrm{IOP}$ [4].

\subsection{Statistical analysis}

Sample size was calculated using power analysis. A pilot study of 10 patients revealed that the average value and standard deviation of IOP measured in the eyes in the LDP were 19.6 and $4.9 \mathrm{mmHg}$, respectively. We assumed that the difference in mean IOP values between both groups was $3.8 \mathrm{mmHg}$ [11]. At the 0.05 level $(=\alpha)$ with a power $(1-\beta)$ of 0.8 , we calculated that the study required a minimum of 14 patients. Data are expressed as mean \pm SD. Mann-Whitney U test was used for betweengroup comparisons. Categorical data were compared using Fisher's exact test. The correlation coefficient between IOP and $\mathrm{mBP} / \mathrm{ETCO}_{2}$ was calculated. Comparisons of measured variables, such as hemodynamic and IOP values, were made using two-way factorial analysis of variance 
(ANOVA) with repeated measures, followed by the Student-Newmann-Keuls test for multiple comparisons. $P<0.05$ was considered a significant difference.

\section{Results}

No complications related to IOP measurements were noted intraoperatively or postoperatively. Table 1 shows the demographic variables of patients in the sevoflurane and propofol groups. There was no difference in age, sex, height, weight, body mass index (BMI), preoperative value of hemoglobin, and pre-existing comorbidity, including hypertension and diabetes mellitus. None of the patients had hyperlipidemia. Table 2 shows the intraoperative variables in each group. There were also no significant differences in the duration of anesthesia, operation, and LDP, nor were there differences in the total amount of blood loss and urine output. Table 3 shows the hemodynamic variables and $\mathrm{ETCO}_{2}$. No difference in these values was identified between the two groups at any time point. No associations were evident between IOP values and $\mathrm{ETCO}_{2}$ in either the sevoflurane group (dependent eye: $r^{2}=0.006, P=0.55$, nondependent eye: $\mathrm{r}^{2}=0.04, P=0.12$ ) or the propofol group (dependent eye: $\mathrm{r}^{2}=0.05, P=0.08$, non-dependent eye: $\left.\mathrm{r}^{2}=0.05, P=0.07\right)$. Moreover, there was no association between IOP values and $\mathrm{mBP}$ in either the sevoflurane group (dependent eye: $\mathrm{r}^{2}=0.02, P=0.30$, non-dependent eye: $\mathrm{r}^{2}=0.02, P=0.78$ ) or the propofol group (dependent eye: $\mathrm{r}^{2}=0.02, \quad P=0.27, \quad$ non-dependent eye: $\mathrm{r}^{2}=0.05$, $P=0.06)$.

Figure 1 shows the IOP changes in the dependent and non-dependent eye in each group. In the sevoflurane group,

Table 1 Demographic data of patients

\begin{tabular}{llll}
\hline & $\begin{array}{l}\text { Sevoflurane } \\
(\mathrm{n}=14)\end{array}$ & $\begin{array}{l}\text { Propofol } \\
(\mathrm{n}=14)\end{array}$ & $P$ \\
\hline Age (year) & $63.5 \pm 16.0$ & $66.1 \pm 7.5$ & 0.58 \\
Male & 7 & 6 & 0.73 \\
Height $(\mathrm{cm})$ & $156.7 \pm 8.3$ & $157.3 \pm 7.7$ & 0.80 \\
Weight $(\mathrm{kg})$ & $52.7 \pm 9.9$ & $56.4 \pm 10.1$ & 0.73 \\
BMI & $21.3 \pm 2.6$ & $22.7 \pm 3.0$ & 0.21 \\
Hemoglobin(g/dl) & $12.1 \pm 1.6$ & $12.7 \pm 1.9$ & 0.40 \\
Hypertension & 5 & 9 & 0.16 \\
(W. medication) & 4 & 6 & 0.47 \\
Diabetes mellitus & 2 & 1 & 0.61 \\
(W. medication) & 1 & 1 & 1.00 \\
Lung Operation & 10 & 11 & 0.69 \\
Other Operation & 4 & 3 &
\end{tabular}

Data are shown as mean \pm SD or as the number. Statistical analyses were performed using the Mann-Whitney U test or Fisher's exact test
Table 2 Intraoperative data

\begin{tabular}{llll}
\hline & $\begin{array}{l}\text { Sevoflurane } \\
(\mathrm{n}=14)\end{array}$ & $\begin{array}{l}\text { Propofol } \\
(\mathrm{n}=14)\end{array}$ & $P$ \\
\hline Anesthesia time (min) & $255 \pm 61$ & $301 \pm 93$ & 0.18 \\
Operation time (min) & $189 \pm 60$ & $242 \pm 93$ & 0.11 \\
Duration of prone position (min) & $214 \pm 61$ & $267 \pm 90$ & 0.13 \\
Blood loss (mL) & $666 \pm 1744$ & $143 \pm 193$ & 0.29 \\
Urine output (mL) & $697 \pm 568$ & $681 \pm 696$ & 0.68 \\
\hline
\end{tabular}

Data are shown as mean \pm SD. Statistical analyses were performed by the Mann-Whitney U test

Table 3 Hemodynamic variables and $\mathrm{ETCO}_{2}$

\begin{tabular}{llll}
\hline & $\begin{array}{l}\text { Sevoflurane } \\
(\mathrm{n}=14)\end{array}$ & $\begin{array}{l}\text { Propofol } \\
(\mathrm{n}=14)\end{array}$ & $P$ \\
\hline mBP (mmHg) & & & \\
T1: control & $87 \pm 9$ & $87 \pm 21$ & 0.74 \\
T2: intubation & $75 \pm 13$ & $70 \pm 12$ & 0.42 \\
T3: lateral & $79 \pm 17$ & $71 \pm 14$ & 0.16 \\
T4: lateral 1 h & $76 \pm 12$ & $78 \pm 13$ & 0.68 \\
T5: supine & $82 \pm 13$ & $79 \pm 17$ & 0.63 \\
Heart rate $(b p m)$ & & & \\
T1 & $75 \pm 23$ & $72 \pm 13$ & 0.64 \\
T2 & $68 \pm 22$ & $71 \pm 14$ & 0.61 \\
T3 & $67 \pm 17$ & $71 \pm 14$ & 0.52 \\
T4 & $72 \pm 14$ & $77 \pm 11$ & 0.43 \\
T5 & $73 \pm 15$ & $75 \pm 11$ & 0.68 \\
ETCO $(m m H g)$ & & & \\
T1 & $27 \pm 6$ & $31 \pm 6$ & 0.07 \\
T2 & $32 \pm 6$ & $34 \pm 6$ & 0.26 \\
T3 & $36 \pm 3$ & $32 \pm 6$ & 0.07 \\
T4 & $34 \pm 5$ & $34 \pm 6$ & 0.81 \\
T5 & $34 \pm 6$ & $34 \pm 6$ & 0.87 \\
\hline Da & & &
\end{tabular}

Data are shown as mean $\pm \mathrm{SD}$. There was no difference in $\mathrm{mBP}$, heart rate and $\mathrm{ETCO}_{2}$ between the sevoflurane and propofol groups at any time point

the IOP values in the dependent eye measured $1 \mathrm{~h}$ after LDP were greater than control values (One-way ANOVA post hoc Student-Newman-Keuls test, $P<0.001$ ). In addition, IOP values in the non-dependent eye measured $1 \mathrm{~h}$ after LDP were greater than control values $(P<0.05)$. In contrast, these changes were not observed in the propofol group. Interestingly, in the propofol group, IOP values after tracheal intubation in both dependent and nondependent eyes were smaller than control values $(P<0.05)$. IOP values in the independent eye measured $1 \mathrm{~h}$ after LDP were significantly greater in the sevoflurane group than in the propofol group (Table $4(P<0.05)$. Moreover, the number of patients exhibiting an IOP of 

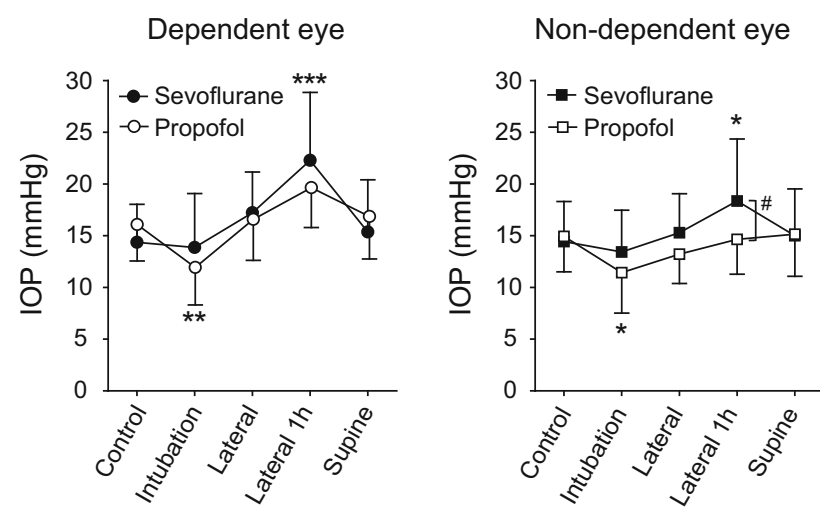

Fig. 1 Changes in intraocular pressure (IOP) under sevoflurane and propofol anesthesia Open and solid circles indicate IOP measured in the dependent eye under sevoflurane and propofol anesthesia, respectively. Open and solid squares indicate IOP measured in the non-dependent eye under sevoflurane and propofol anesthesia, respectively. $* P<0.05$. $* * P<0.01, * * * P<0.001$ versus control within a group. ${ }^{\#} P<0.05$ between sevoflurane and propofol groups

greater than or equal to $28 \mathrm{mmHg}$, measured $1 \mathrm{~h}$ after LDP, were greater in the sevoflurane group than in the propofol group, Fisher's exact test, $P<0.05$ ). No difference in OPP values of dependent or non-dependent eyes were seen between sevoflurane and propofol groups at any time point (Table 4). Fortunately, no patients in either group experienced ophthalmic complications, such as visual loss or visual field constriction, postoperatively (Table 5).

\section{Discussion}

This study showed that IOP values increase in the LDP under sevoflurane but not propofol anesthesia. Although there was no statistically significant difference in IOP values between sevoflurane and propofol groups, an abnormal increase in IOP (i.e. $\geq 28 \mathrm{mmHg}$ ) in the LDP was more prominent in the sevoflurane group than in the propofol group. This evidence suggests that propofol may be better than sevoflurane for maintenance of anesthesia during surgery performed in the LDP.

One important finding of this study was the increase in IOP in the LDP under sevoflurane anesthesia. This was consistent with a previous report [11]. In contrast, an increase in IOP in the LDP was not observed under propofol anesthesia. These distinct effects of anesthetics on IOP may be explained as follows. It is postulated that change in body position from supine to lateral increased IOP. Increase in choroidal vascular volume and episcleral venous pressure may play an important role in the increase in IOP in the LDP as well as prone position [11]. Several previous studies, as well as our results, indicate that propofol itself appears to decrease IOP [13, 14, 17]. While
Table 4 IOP and OPP values

\begin{tabular}{|c|c|c|c|}
\hline & $\begin{array}{l}\text { Sevoflurane } \\
(\mathrm{n}=14)\end{array}$ & $\begin{array}{l}\text { Propofol } \\
(\mathrm{n}=14)\end{array}$ & $P$ \\
\hline \multicolumn{4}{|c|}{ IOP of dependent eye $(\mathrm{mmHg})$} \\
\hline T1: control & $14.4 \pm 3.7$ & $16.0 \pm 3.5$ & 0.31 \\
\hline $\mathrm{T} 2$ : intubation & $13.9 \pm 5.2$ & $11.9 \pm 3.6$ & 0.25 \\
\hline T3: lateral & $17.2 \pm 3.9$ & $16.6 \pm 4.0$ & 0.70 \\
\hline T4: lateral $1 \mathrm{~h}$ & $22.3 \pm 6.6$ & $19.6 \pm 3.9$ & 0.12 \\
\hline T5: supine & $15.4 \pm 5.0$ & $16.9 \pm 4.1$ & 0.38 \\
\hline \multicolumn{4}{|c|}{ IOP of independent eye (mmHg) } \\
\hline $\mathrm{T} 1$ & $14.4 \pm 3.9$ & $14.9 \pm 3.4$ & 0.75 \\
\hline $\mathrm{T} 2$ & $13.4 \pm 4.0$ & $11.4 \pm 4.0$ & 0.20 \\
\hline $\mathrm{T} 3$ & $15.3 \pm 3.8$ & $13.2 \pm 2.8$ & 0.18 \\
\hline $\mathrm{T} 4$ & $18.4 \pm 6.0$ & $14.6 \pm 3.4$ & 0.02 \\
\hline T5 & $15.0 \pm 4.5$ & $15.1 \pm 4.0$ & 0.93 \\
\hline \multicolumn{4}{|c|}{ OPP of dependent eye $(\mathrm{mmHg})$} \\
\hline $\mathrm{T} 1$ & $62.5 \pm 8.7$ & $62.3 \pm 18.0$ & 0.98 \\
\hline $\mathrm{T} 2$ & $52.4 \pm 10.9$ & $50.4 \pm 10.1$ & 0.68 \\
\hline $\mathrm{T} 3$ & $52.5 \pm 13.3$ & $46.3 \pm 13.1$ & 0.21 \\
\hline $\mathrm{T} 4$ & $44.5 \pm 11.1$ & $49.1 \pm 13.7$ & 0.35 \\
\hline T5 & $57.1 \pm 10.3$ & $53.3 \pm 14.3$ & 0.43 \\
\hline \multicolumn{4}{|c|}{ OPP of independent eye $(\mathrm{mmHg})$} \\
\hline $\mathrm{T} 1$ & $62.4 \pm 9.6$ & $63.5 \pm 17.8$ & 0.83 \\
\hline $\mathrm{T} 2$ & $52.8 \pm 12.2$ & $50.9 \pm 10.0$ & 0.70 \\
\hline $\mathrm{T} 3$ & $54.4 \pm 15.6$ & $49.7 \pm 13.2$ & 0.34 \\
\hline $\mathrm{T} 4$ & $48.4 \pm 12.1$ & $54.1 \pm 13.3$ & 0.26 \\
\hline T5 & $57.5 \pm 12.0$ & $55.0 \pm 13.7$ & 0.62 \\
\hline
\end{tabular}

Data are shown as mean \pm SD

Table 5 Number of patients exhibiting high IOP

\begin{tabular}{llcl}
\hline Anesthetics & \multicolumn{2}{l}{ No. of Patients } & $\begin{array}{l}\text { Fisher's exact test } \\
P \text { value }\end{array}$ \\
\cline { 2 - 3 } & IOP $\geq 28$ & IOP $<28$ & \\
\hline Sevoflurane & 5 & 9 & 0.04 \\
Propofol & 0 & 14 & \\
\hline
\end{tabular}

the reducing effect of propofol on IOP may mask the increasing effect of LDP on IOP, the increasing effect of LDP may be dominant under sevoflurane anesthesia. The mechanisms of how anesthetics directly affect IOP are not known. Therefore, further studies are required to clarify this issue.

A past study suggested a correlation between $\mathrm{PaCO}_{2}$ and IOP in patients who underwent laparoscopic surgery under halothane and $\mathrm{N}_{2} \mathrm{O}$ anesthesia [18]. In the current study, we investigated the relationship between IOP and $\mathrm{ETCO}_{2}$ instead of $\mathrm{PaCO}_{2}$. There was no correlation between IOP 
and $\mathrm{ETCO}_{2}$. This result was probably due to control of $\mathrm{ETCO}_{2}$ within a relatively narrower range compared to the past study (25-40 vs. $15-90 \mathrm{mmHg}$, respectively). We also examined the relationship between IOP and $\mathrm{mBP}$, which was maintained within $\pm 20 \%$ of the preoperative value. There was no correlation between $\mathrm{mBP}$ and IOP, which is consistent with a past report [19]. As shown in Table 3, there was no difference in hemodynamic variables and $\mathrm{ETCO}_{2}$ between the sevoflurane and propofol groups. Taken together, the distinct effect of anesthetics on IOP is likely to result from the anesthetics per se rather than their secondary effect on hemodynamic variables.

We reported here that OPP values did not differ between the sevoflurane and propofol groups. This result suggests that these anesthetic agents show little difference in maintaining an appropriate OPP. This may simply reflect the lack of difference in $\mathrm{mBP}$, which is directly related to OPP, between groups. Holding an adequate OPP during surgery in the LDP is likely to be important to prevent development or progression of ischemic optic neuropathy or glaucoma. However, the appropriate range of OPPs for which anesthesiologists should aim during surgery remains unclear. Further study is needed to clarify the relationship between control of OPP during surgery and occurrence of POVL after surgery.

One of the limitations of the current study was the lack of depth-of-anesthesia monitoring. Depth of anesthesia was controlled based on standard clinical monitoring practices. None of the patients complained of intraoperative awareness. We believe that there was no significant difference in the depth of anesthesia, because hemodynamic variables did not differ between the groups at any time point. However, some objective measures, such as BIS value, should be monitored to evaluate depth of anesthesia. Another limitation is the heterogeneous population of subjects. Although nearly $80 \%$ of patients in both groups underwent lung operations, the remaining patients underwent various surgeries, including nephrectomy and lower limb surgery. The ratio of lung to other operations in both groups was not different, as shown in Table 1. Therefore, we believe that the effect of the heterogeneous population of subjects on the changes in IOP in the LDP would be negligible. Based on the self-reported history, patients who had glaucoma and ophthalmic disease other than myopia or hypermetropia were excluded. The maximum IOP measured at T1 in both groups was $21 \mathrm{mmHg}$. Normal IOP in the Japanese population is reportedly between 10 and $21 \mathrm{mmHg}$ [20]. Taken together, we believe that no patients with glaucoma and high IOP were included in this study. However, we did not perform comprehensive ophthalmic examinations before the operation, so we cannot exclude the possibility that patients with mild to moderate glaucoma or ocular hypertension may have been included. IOP measurements should have been performed by observers blinded to study groupings, but were not in this study.

Risk factors of POVL include male sex, obesity, use of the Wilson spinal frame, longer anesthesia duration, greater blood loss, and a lower percentage of colloid in the nonblood fluid administered [7]. Some of these risk factors appear to be common for other ophthalmic complications after operations performed in the LDP. In our study, none of the patients complained of ophthalmic complications despite the abnormal increase in IOP in some of the patients. Patients with pre-existing ophthalmic conditions, including glaucoma, were excluded from the current study. Moreover, patients with a high risk of POVL, such as obesity and long operation time, were not included. These factors might have contributed to the absence of ophthalmic complications. The current study suggested that physicians should be cautious when patients undergo surgery in the LDP.

Acknowledgments This work was supported by JSPS KAKENHI Grant Numbers 17591614, 20390411, 20659242.

Open Access This article is distributed under the terms of the Creative Commons Attribution 4.0 International License (http://creative commons.org/licenses/by/4.0/), which permits unrestricted use, distribution, and reproduction in any medium, provided you give appropriate credit to the original author(s) and the source, provide a link to the Creative Commons license, and indicate if changes were made.

\section{References}

1. Lee JY, Yoo C, Jung JH, Hwang YH, Kim YY. The effect of lateral decubitus position on intraocular pressure in healthy young subjects. Acta Ophthalmol. 2012;90(1):e68-72. doi:10.1111/j. 1755-3768.2011.02208.x.

2. Malihi M, Sit AJ. Effect of head and body position on intraocular pressure. Ophthalmology. 2012;119(5):987-91. doi:10.1016/j. ophtha.2011.11.024.

3. Lee JY, Yoo C, Kim YY. The effect of lateral decubitus position on intraocular pressure in patients with untreated open-angle glaucoma. Am J Ophthalmol. 2013;155(2):329-335.e2. doi:10. 1016/j.ajo.2012.08.003.

4. Lee TE, Yoo C, Kim YY. Effects of different sleeping postures on intraocular pressure and ocular perfusion pressure in healthy young subjects. Ophthalmology. 2013;120(8):1565-70. doi:10. 1016/j.ophtha.2013.01.011.

5. Kim KN, Jeoung JW, Park KH, Lee DS, Kim DM. Effect of lateral decubitus position on intraocular pressure in glaucoma patients with asymmetric visual field loss. Ophthalmology. 2013;120(4):731-5. doi:10.1016/j.ophtha.2012.09.021.

6. Piven I, Glovinsky Y. Intraocular pressure curves of untreated glaucoma suspects and glaucoma patients in sitting and lateral decubitus positions using the goldmann applanation tonometer. J Glaucoma. 2014;23(8):541-6. doi:10.1097/IJG.0000000000000084.

7. Lee LA. Perioperative visual loss and anesthetic management. Curr Opin Anaesthesiol. 2013;26(3):375-81. doi:10.1097/ACO. 0b013e328360dcd9.

8. Roth S. Perioperative visual loss: what do we know, what can we do? Br J Anaesth. 2009;103(Suppl 1):i31-40. doi:10.1093/bja/ aep295. 
9. Heitz JW, Audu PB. Asymmetric postoperative visual loss after spine surgery in the lateral decubitus position. $\mathrm{Br} \mathrm{J}$ Anaesth. 2008;101(3):380-2. doi:10.1093/bja/aen163.

10. Lee LA, Roth S, Posner KL, Cheney FW, Caplan RA, Newman NJ, Domino KB. The American Society of Anesthesiologists Postoperative Visual Loss Registry: analysis of 93 spine surgery cases with postoperative visual loss. Anesthesiology. 2006;105(4):652-9 (quiz 867-8).

11. Hwang JW, Jeon YT, Kim JH, Oh YS, Park HP. The effect of the lateral decubitus position on the intraocular pressure in anesthetized patients undergoing lung surgery. Acta Anaesthesiol Scand. 2006;50(8):988-92. doi:10.1111/j.1399-6576.2006.01050.x.

12. Sator-Katzenschlager S, Deusch E, Dolezal S, Michalek-Sauberer A, Grubmuller R, Heinze G, Wedrich A. Sevoflurane and propofol decrease intraocular pressure equally during non-ophthalmic surgery and recovery. Br J Anaesth. 2002;89(5):764-6.

13. Mowafi HA, Al-Ghamdi A, Rushood A. Intraocular pressure changes during laparoscopy in patients anesthetized with propofol total intravenous anesthesia versus isoflurane inhaled anesthesia. Anesth Analg. 2003;97(2):471-4.

14. Schafer R, Klett J, Auffarth G, Polarz H, Volcker HE, Martin E, Bottiger BW. Intraocular pressure more reduced during anesthesia with propofol than with sevoflurane: both combined with remifentanil. Acta Anaesthesiol Scand. 2002;46(6):703-6.
15. Sugata A, Hayashi H, Kawaguchi M, Hasuwa K, Nomura Y, Furuya $\mathrm{H}$. Changes in intraocular pressure during prone spine surgery under propofol and sevoflurane anesthesia. J Neurosurg Anesthesiol. 2012;24(2):152-6. doi:10.1097/ANA. 0b013e31823fe822.

16. Leske MC. Ocular perfusion pressure and glaucoma: clinical trial and epidemiologic findings. Curr Opin Ophthalmol. 2009;20(2):73-8. doi:10.1097/ICU.0b013e32831eef82.

17. Inoue Y, Shibuya I, Kabashima N, Noguchi J, Harayama N, Ueta Y, Sata T, Shigematsu A, Yamashita H. The mechanism of inhibitory actions of propofol on rat supraoptic neurons. Anesthesiology. 1999;91(1):167-78.

18. Hvidberg A, Kessing SV, Fernandes A. Effect of changes in $\mathrm{PCO} 2$ and body positions on intraocular pressure during general anaesthesia. Acta Ophthalmol (Copenh). 1981;59(4):465-75.

19. Riva CE, Sinclair SH, Grunwald JE. Autoregulation of retinal circulation in response to decrease of perfusion pressure. Invest Ophthalmol Vis Sci. 1981;21(1 Pt 1):34-8.

20. Iwase A, Suzuki Y, Araie M, Yamamoto T, Abe H, Shirato S, Kuwayama Y, Mishima HK, Shimizu H, Tomita G, Inoue Y, Kitazawa Y, Tajimi Study Group JGS. The prevalence of primary open-angle glaucoma in Japanese: the Tajimi Study. Ophthalmology. 2004;111(9):1641-8. doi:10.1016/j.ophtha.2004.03.029. 